\title{
Reply to Letter to the Editor
}

\section{In Brief}

\section{Crowe's Classification: Arthroplasty in Developmental Dysplasia of the Hip}

\author{
Muhammad Umar Jawad MD, Sean P. Scully MD, PhD
}

Published online: 16 October 2010

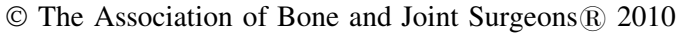

Reply:

We are grateful to Drs. Wu and Lin for reading our article entitled: In Brief: Crowe's Classification: Arthoplasty in Developmental Dysplasia of the Hip [2]. They correctly pointed out errors in Table 1 of the article. We agree that Group I should read: Subluxation $<50 \%$ or proximal dislocation $<10 \%$ or 0.1 of the pelvic height. Group II should read: Subluxation $50 \%-75 \%$ or proximal dislocation of $10 \%$ to $15 \%$ or $0.1-0.15$ of pelvic height. Group III should read: Subluxation $75 \%-100 \%$ or proximal dislocation of $15 \%$ to $20 \%$ or $0.15-0.2$ of pelvic height. Group IV should read: Subluxation $>100 \%$ or proximal dislocation of $>20 \%$ or 0.2 of pelvic height [1]. The text of the manuscript, however, describes this classification without the above-mentioned errors. An erratum confirming these changes will be published. Once again, we are grateful to Drs. Wu and Lin for bringing this to our attention.

\section{References}

1. Crowe JF, Mani VJ, Ranawat CS. Total hip replacement in congenital dislocation and dysplasia of the hip. J Bone Joint Surg Am. 1979;61:15-23.

2. Jawad M, Scully S. In Brief: Crowe's classification: arthroplasty in developmental dysplasia of the hip. Clin Orthop Relat Res. 2010 Mar 23. [Epub ahead of print]
(Re: Jawad M, Scully S. In Brief: Crowe's classification: arthroplasty in developmental dysplasia of the hip. Clin Orthop Relat Res. 2010 Mar 23. [Epub ahead of print].)

M. U. Jawad

Orthopaedic Surgery, Stanford Hospital, Stanford, CA, USA

S. P. Scully $(\bowtie)$

Department of Orthopaedics, University of Miami Miller School of Medicine, 1400 NW, 12th Avenue, Miami, FL 33136, USA

e-mail: sscully@med.miami.edu; sean.p.scully@gmail.com 